\title{
The Comparison Between 2-D and 3-D Slope Stability Analysis Based on Reinforcement Requirements
}

\author{
P.T.K. Sari ${ }^{\mathrm{a}, 1}$, Y.E. Putri ${ }^{\mathrm{a}, 2}$, Y.R. Savitri ${ }^{\mathrm{a}, 3}$, A.R. Amalia ${ }^{\mathrm{a}, 4}$, Nastasia F. Margini ${ }^{\mathrm{a}, 5}$, D.A.D. Nusantara ${ }^{\mathrm{b}}$ \\ ${ }^{a}$ Department of Civil Engineering, Faculty of Civil, Planning and Geo Engineering, Institut Teknologi Sepuluh Nopember, Sukolilo, \\ Surabaya, Indonesia \\ E-mail: ' tantrigeoteknik@gmail.com, 2yusroniya.putri@gmail.com,33yangratrisavitri@gmail.com, 4 aniendhita.ra@gmail.com, \\ 5 cia.hidroits@gmail.com \\ ${ }^{b}$ Department of Civil Engineering, Faculty of Engineering, Universitas Negeri Surabaya, Ketintang, Surabaya, Indonesia \\ E-mail: azmidewi@gmail.com
}

\begin{abstract}
The landslides in the field often do not have an infinite length, making 3-dimensional assumptions more appropriate for the design. Meanwhile, they are mostly analyzed in design by assuming the landslides occur infinitely with plane strain in a 2dimensional approach. This assumption becomes less precise due to the consideration of the safety factor based on 2-dimensional conditions while the landslide happens 3-dimensional, and this has further effects on the need for reinforcement. This research was conducted to determine the level of influence 2-dimensional and 3-dimensional landslide safety factors have on the number of reinforcements required. A limit equilibrium method was used in the study. The number of geotextile reinforcement needs with a 3dimensional sliding model is calculated based on existing research results. The results are then compared with the amount of geotextile reinforcement required with a 2-dimensional sliding model. The results showed the possibility of having the same amount of reinforcement under 2-D and 3-D assumptions in the homogeneous soil, while different results were found with heterogeneous soil layers due to the variations in soil conditions. Comparison of the number of geotextile reinforcement requirements between 2 dimensions and three dimensions still needs to be further developed by using more varied soil data. This is done considering that existing studies are only limited to soil, which tends to be homogeneous.
\end{abstract}

Keywords - slope stability; 3-D landslide; 2-D landslide; geotextile reinforcement.

\section{INTRODUCTION}

Most of the embankment stability analysis in construction design is usually conducted using a two-dimensional (2-D) method with a limit equilibrium approach. This involved computing the safety factor against landslides by assuming plane-strain conditions. The assumption is based on sliding occurring in the field has an infinite length in order to neglect the effect of those in three dimensions (3-D). Meanwhile, they are not always infinite, making the 2-D calculation assumptions less appropriate for this condition. However, some researchers found the use of 2-D analysis fitting for slope design due to its ability to yield a conservative estimate for the safety factor whose end effects are not included while the other recommended 3-D method for back analysis in order to be able to describe the condition of its end effects using back-calculated shear strength.

The research on slope stability in soil and rocks using a 3dimensional approach has been increasingly conducted with the 3-D slope stability calculation method observed to be first introduced by Anagnosti in 1969 by developing the 2-D stability analysis designed by Morgenstern in 1965 and implemented using the limit equilibrium approach. The 2-D slope stability method has been developed to calculate the stability of 3-D slope by several researchers, but the studies are different from each other based on the assumption of landslide fields occurring in 3-D. Some were observed to have assumed the slip plane is a circular cross-section while others used a cylindrical cross-section.

Several researchers have conducted 3-D slope landslide research as development on 2-D landslides from the 60s to the present., 2-D is used for theoretical slope stability based on Spencer method [1] while other researchers developed the theory in line with Fellenius Method [2]. Moreover, the 2-D slope stability research of Bishop method has been improved to 3-D [3]. Other researcher developed the 2-D theoretical basis used by Morgenstern and Price [4], while other researchers formulated the Janbu simplified method and Janbu Generalised methods [5], [6]. 
Baligh and Azzouz were the first to present a 3dimensional slope stability study on cohesive soils using the circular arc method in which landslides were assumed to be a combination of cylindrical center points with conical ends. Moreover, Chen and Chameau [7] presented a 3D method to analyze slope stability inhomogeneous and frictional slope cohesive soils by considering force and moment equilibrium with different pore water pressure conditions. The result showed the safety factor with the 3-D method is higher than 2-D. Another research assumed landslide fields are a combination of cylindrical center parts followed by curve ends to calculate the safety factor value and the figure recorded for 3-D slope stability was found to be higher than $2-\mathrm{D}$ at 1.03 to 1.30 . Furthermore, Bjerrum also reported the ratio of the 3-D and 2-D safety factor to be 1.07-1.30.

The natural slope researched [8] found the ratio of 3-D and 2-D safety factor to have an average value of 1.44 while another study produced a ratio of 1.76 in undrained uniform slope, 1.15 in undrained cut slopes, and 1.04 in undrained natural slope when $\mathrm{L} / \mathrm{H}=5$ using a limit analysis method [9]. Dana et al. [10] also conducted a comparative analysis of the safety factors in the open-pit mines area, and all the conditions analyzed were reported to have values of more than 1 , with the steep slope having 1.29 and the gentle slope estimated at 1.17 .

Other studies regarding comparing $2 \mathrm{D}$ and $3 \mathrm{D}$ slope stability have also been conducted by several researchers, namely [11]-[17], which show differences in results, between $2 \mathrm{D}$ and $3 \mathrm{D}$ slope stability. Most of these results showed the 3-D and 2-D safety factor ratio to be more than one under certain conditions. Hovland [18] was also reported to have concluded the safety factor for 3-D is higher than 2$\mathrm{D}$ for cohesive soils and lesser for non-cohesive soils, and similar results were obtained [7]. This means an increase in the failure surface's length causes a reduction in the safety factor ratio. The research also showed the ratio was reduced with the steeper slope. According to Lovell (1984), higher pore water pressure can cause the 3-D/2-D safety factor in cohesive soils to decrease slightly as the cylinder length increases. A summary of the results from previous studies is presented in Table 1 and, despite several debates, they are still being used as references in subsequent studies.

TABLE I

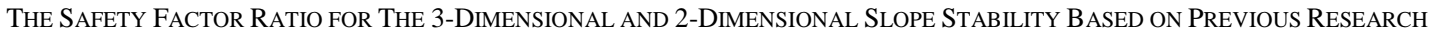

\begin{tabular}{|c|c|c|}
\hline Procedure & Theoretical basis & 3-D/2-D \\
\hline \multirow{4}{*}{$\begin{array}{l}\text { Chen and Chameau (1983) } \\
\text { Thomas and Lovell (1988) } \\
\text { Chen et al (2003) } \\
\text { Jiang and Yamagami (2004) }\end{array}$} & \multirow[t]{4}{*}{ Spencer (1967) } & $>1$ for cohesive soil; $<1$ for non-cohesive soil \\
\hline & & $>1$ for cohesive soil not always for non-cohesive soil \\
\hline & & $>1$ \\
\hline & & $>1$ \\
\hline \multirow{5}{*}{$\begin{array}{l}\text { Baligh and Azzouz (1975) } \\
\text { Hovland (1977) } \\
\text { Ugai (1988) } \\
\text { Gent et al. (1988) } \\
\text { Xing (1988) }\end{array}$} & \multirow{5}{*}{$\begin{array}{l}\text { Fellenius (1922) } \\
\text { Fellenius (1927) } \\
\text { Fellenius (1936) } \\
\text { Fellenius (1922) } \\
\text { Fellenius (1927) }\end{array}$} & $>1$ \\
\hline & & $>1$ for cohesive soil; < 1 for non-cohesive soil \\
\hline & & $>1$ for cohesive soil; < 1 for non-cohesive soil \\
\hline & & $>1$ \\
\hline & & $>1$ \\
\hline \multirow{5}{*}{$\begin{array}{l}\text { Hungr (1987) } \\
\text { Ugai (1988) } \\
\text { Hungr et al. (1989) } \\
\text { Huang and Tsai (2000) } \\
\text { Cheng and Yip (2007) }\end{array}$} & \multirow[t]{5}{*}{ Bishop (1955) } & $>1$ \\
\hline & & $>1$ for cohesive soil; < 1 for non-cohesive soil \\
\hline & & $>1$ \\
\hline & & $>1$ \\
\hline & & $>1$ \\
\hline $\begin{array}{l}\text { Anagnosti (1969) } \\
\text { Hungr (2001) } \\
\text { Sun et al. (2012) } \\
\text { Cheng and Yip (2007) } \\
\end{array}$ & $\begin{array}{l}\text { Morgenstern and } \\
\text { price (1965) }\end{array}$ & $>1$ \\
\hline $\begin{array}{l}\text { Hungr et al. (1989) } \\
\text { Huang et al. (2002) } \\
\text { Cheng and Yip (2007) }\end{array}$ & $\begin{array}{l}\text { Janbu simplified } \\
\text { (1965 and 1973) }\end{array}$ & $>1$ \\
\hline
\end{tabular}

Previous studies have shown the safety factor values obtained from 3-D and 2-D methods are different based on the type of soil, landslide field assumptions, and slope dimensions. It is important to note that the safety factor affects the slope treatment when designing the reinforcement required. Therefore, this present research discusses the influence of the safety factor differences in designing the reinforcement needs for slope stability design using the ratio from previous studies. This research's primary outcome was to determine how vital 3-D analysis is conducted to replace the 2-D analysis in different aspects.

\section{MATERIALS AND METHOD}

\section{A. 2-Dimensional Slope Stability Analysis}

The limit equilibrium method for 2D slope stability analysis is divisible into three procedures: slice, circular, and non-circular. Meanwhile, the vertical slice procedure using Bishop method, Fellenius Method, Janbu Method, Morgenstern Method, and Sarma Method are mostly applied due to its two useful simplifications. It includes the base of each slice passing through only one type of material and the slices narrow enough to ensure a straight line can model the slip surface at each slice base. The circular and non-circular 
procedures are considered less accurate due to their consideration of the whole failing mass's equilibrium.

Two different slices procedures were developed by Bishop method and they include Bishop complete and Bishop simplified procedures. The horizontal and vertical forces acting on the slice's sides are included in the complete procedure, but, based on [19], this theory does not specify the fully satisfied statistic equilibrium in its assumption. Moreover, the simplified procedure neglects the interslice shear forces, while those on the sides of slices are assumed to be horizontal. It also uses overall moment equilibrium about a center of rotation and the vertical force equilibrium equation of each slice to determine the unknown forces.

Janbu method also developed the theory of the Generalized Procedure of Slices (GPS), which was observed not to satisfy the moment rigorously but only force equilibrium and this means it does not meet all the required conditions. Another theory develop by Janbu is the Simplified procedure which assumes of horizontal interslice forces while the normal force is derived from the summation of forces in the vertical direction with interslice shear forces ignored. Moreover, Spencer's procedure satisfies all conditions of equilibrium including horizontal and vertical force and the moment and was initially developed for circular surfaces before being extended to non-circular ones. This theory assumes all interslice forces have the same inclination. Morgenstern Method presents another rigorous procedure that assumes that the shear force between slices is related to the normal force.

\section{B. 3-Dimensional Slope Stability Analysis}

Several researchers have proposed the 3-D slope stability theory since 1960 with most observed to have used the limit equilibrium procedure. Still, the number is relatively few compared to the 2-D analysis with the same procedure. However, there is the need for more assumptions to extend the 2-D limit equilibrium procedure using 3-D with the two observed to be different in their 1) assumptions of inter column forces, 2) equilibrium equation and 3) simplification of the failure surface shape.

An initial concept to evaluate 3-D effects is using the weighted average procedure developed by [20] which suggests using parallel cross-sections through the slope. This involved the calculation of the safety factor in each of the three parallel cross-sections using 2-D slope stability analysis after which a weighted 3-D safety factor is computed using the weight above the failure surface in each cross-section as the weighing factor as shown in Figure 1 and with the following equation:

$$
F=\frac{F_{1} \cdot A_{1}+F_{2} \cdot A_{2}+F_{3} \cdot A_{3}}{A_{1}+A_{2}+A_{3}}
$$

$\mathrm{F}$ and $\mathrm{A}$ with subscripts represent the $\mathrm{F}, \mathrm{S}$, and weight, respectively, for the 2-D cross-sections. However, this is not a 3-D procedure due to its neglects of forces between the cross-sections but has the potential to produce a good result in the failure surface tapers by gradually moving up towards the boundaries on the sides of the slide mass condition to ensure the three more cross-sections in 2-D perception capture the side force. This procedure is not suitable for translational slides due to the shear resistance on a vertical or near-vertical side, which cannot be modeled using a 2-D cross-section. Moreover, the weighted average in the translational slides yields the same F.S. as the central crosssection, which also makes the procedure unsuitable.
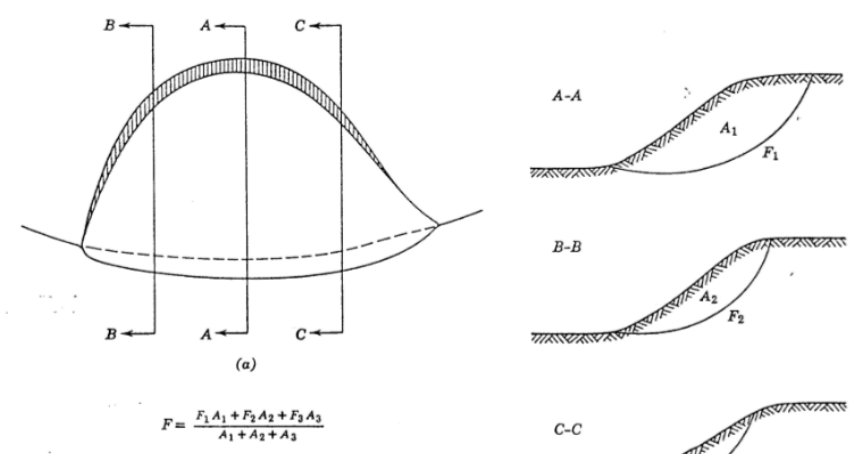

$F=\frac{F_{1} A_{1}+F_{2} A_{2}+F_{3} A_{3}}{A_{1}+A_{2}+A_{3}}$

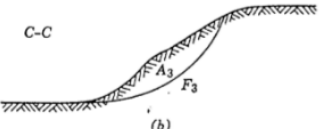

Fig. 1 Weighted average procedure

The concept of 3D slope stability has been effectively developed to express the real 3-D condition after 1970 with several approaches on the failure surface, as shown in Fig. 2. The failure mass above the failure surface is divided into several vertical columns indicated in Figure $3 \mathrm{a}$ with the free body diagram of a column extracted from the failure mass shown in Figure 3b [21]. Several parameters are, however, included in the analysis, such as 1) the normal and shear forces acting on the sides (X-Y plane), ends ( $\mathrm{Y}-\mathrm{Z}$ plane), and base of the column, 2) the points of applying forces, and 3 ) the safety factor of the overall analysis. There are several assumptions for the effective determination of the problem. They include symmetrical failure mass and no movement in the $\mathrm{Z}$ direction to show the horizontal shear stresses acting on the Y-Z plane's base at the onset of failure assumed to be zero. These assumptions are expressed using the following equation:

$$
\begin{gathered}
P i_{, j}=P_{-}, j=0 \\
z, i, j=0
\end{gathered}
$$

$\mathrm{Pi}$, and $\mathrm{Pi}, \mathrm{j}$ act on the ends of the column while $\mathrm{Z}, \mathrm{I}, \mathrm{j}$ acts on the base. Each side or end force is assumed to be acting along the central vertical line since the column dimension, including its length and width, is small enough.

$$
\begin{aligned}
& b, j=b, j=b / 2 \\
& b z i=h d i=1 / 2
\end{aligned}
$$

The shear forces acting on the column sides, Ri,j, Ri,j_ I as shown in Fig. 2, are parallel to the bottom face while the cohesion part of the mobilized shear force $(\mathrm{R}, / \mathrm{F})$ acts at the $\mathrm{h} / 2$ from the base. Meanwhile, the cohesionless part of the mobilized shear force acts at $h / 3$ from the base with the inter-column normal stress distribution assumed to be linear with the depth. 


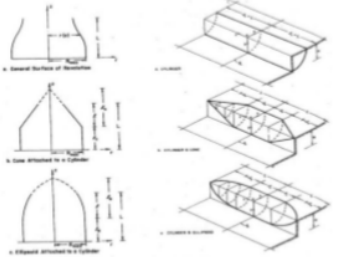

(after Baligh and Azzouz 1975)

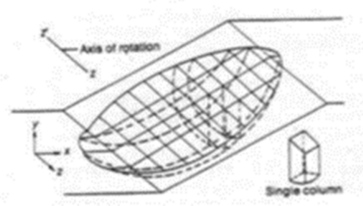

(after Chen and Chameau 1983)

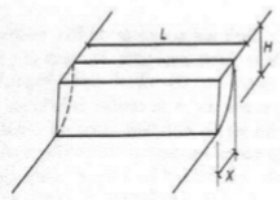

(after Gens et al. 1988)

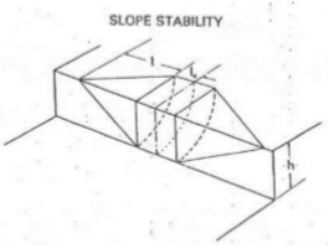

(after Hovland 1977)

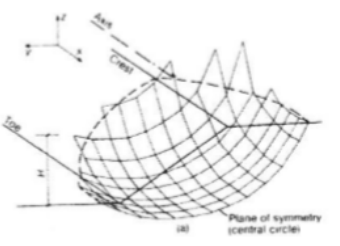

(after Hungr 1987)

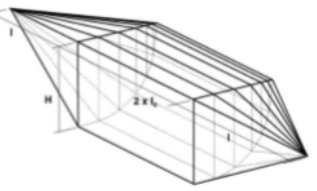

(after Chang 2002)
Fig. 2 Several approaches to failure surface based on a previous study [22].
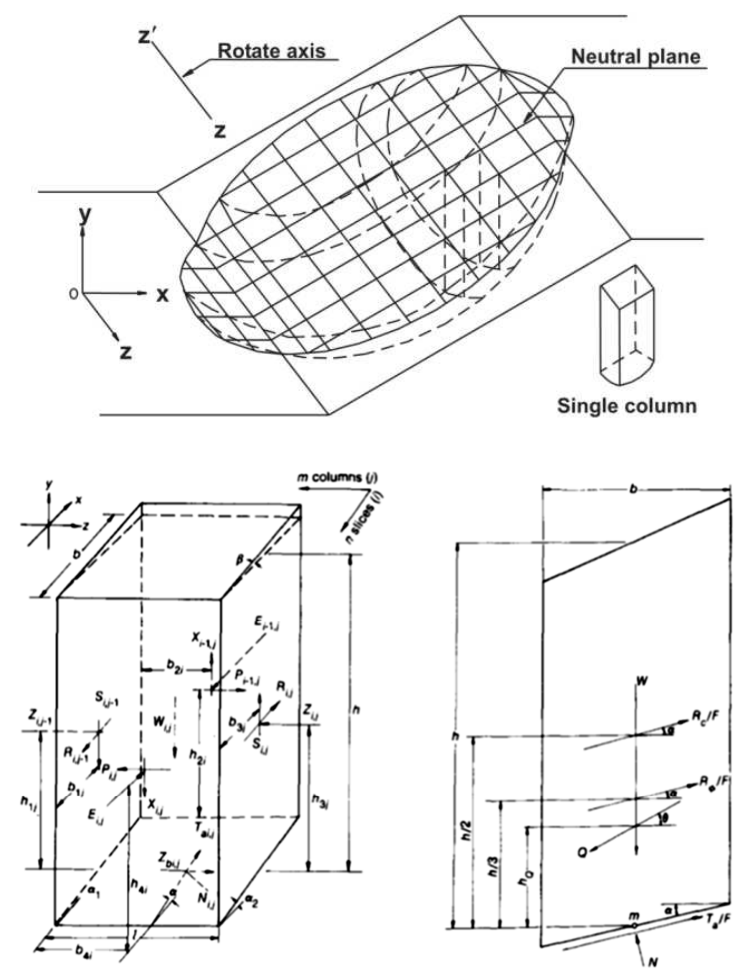

Fig. 3a (top) 3-dimensional failure mass [7]; 3b (bottom) Free body diagram of a column and side view of the force system in a column [7]

Hovland [11] proposed a general approach for threedimensional slope stability analysis. This involves defining the safety factor as the ratio of the total available resistance along a failure surface to the total mobilized stress. The ordinary method of slices was used to simplify the analysis with the inter-column forces ignored. Both normal and shear stresses at each column base were obtained merely as the column's weight component, and it is also possible to present the safety factor in a similar form by dividing the soil mass above the failure surface into several vertical columns. Assume the X.Y. plane to be horizontal, the Z-axis to be vertical, and the $\mathrm{Y}$-axis to be in the direction of downslope movement as shown in Fig. 4 to derive the following equation:

$$
\begin{gathered}
F_{3}=\frac{\sum_{x} \sum_{y}\left[\frac{c \cdot \Delta x \cdot \Delta y \sin \theta}{\cos \alpha_{x z} \cos \alpha_{y z}}+\rho \cdot z \cdot \Delta x \cdot \Delta y \cos (D I P) \tan \varphi\right]}{\sum_{x} \sum_{y} \rho \cdot z \cdot \Delta x \cdot \Delta y \sin \alpha_{y z}} \\
\cos (D I P)=\left(1+\tan ^{2} \alpha_{x z}+\tan ^{2} \alpha_{y z}\right)^{-1 / 2} \\
\sin \theta=\left(1-\sin ^{2} \alpha_{x z .} \sin ^{2} \alpha_{y z .}\right)^{1 / 2}
\end{gathered}
$$

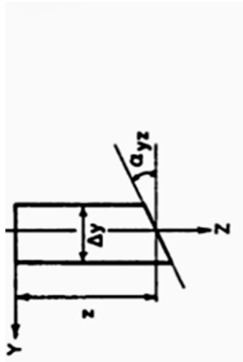

Section
Plan
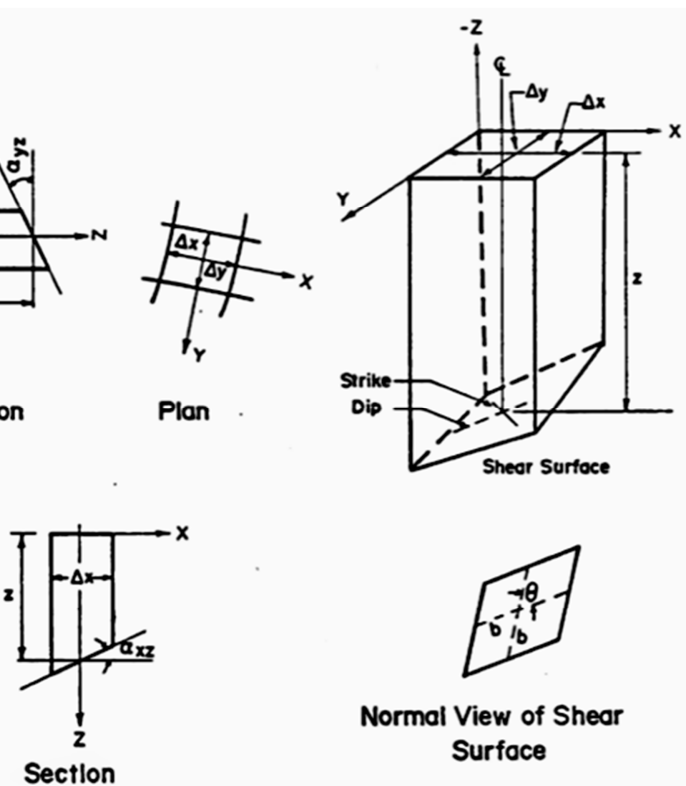

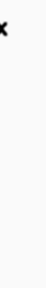

(1)

Fig. 4 Plan section and three-dimensional view on one soil column ([11])

Furthermore, slope stability 3D calculation methods are increasingly being used for calculation applications, although not as much as 2D analysis. Research and the latest state of the art regarding slope stability 3D have been conducted by several researchers [23]-[28]. This research attempts to see how the effectiveness of slope stability 3D analysis compared to $2 \mathrm{D}$ analysis.

\section{RESULTS AND DISCUSSION}

The 2-D slope stability analysis was conducted using the Geo5 program to obtain the safety factor[7] (see Figure 5) and compared to Figure 6 [29]. The soil parameters used in this study were adapted to those applied previous studies and they include $\mathrm{c}=0 ; \phi=40, \mathrm{c}=7.2 \mathrm{Kpa} ; \phi=30, \mathrm{c}=14 \mathrm{Kpa}$; $\phi=25, \mathrm{c}=21.6 \mathrm{Kpa} ; \phi=20$ and $\mathrm{c}=28.7 \mathrm{Kpa} ; \phi=15$. Those parameters are used for all soil layer both surface and sub-surface layer, so that means that this study uses the homogenous soil parameter. The embankment height was 6.1 meters with a slope of $1 \mathrm{v}: 1.5 \mathrm{~h} ; 1 \mathrm{v}: 2.5 \mathrm{~h}$; and $1 \mathrm{v}: 3.5 \mathrm{~h}$. 

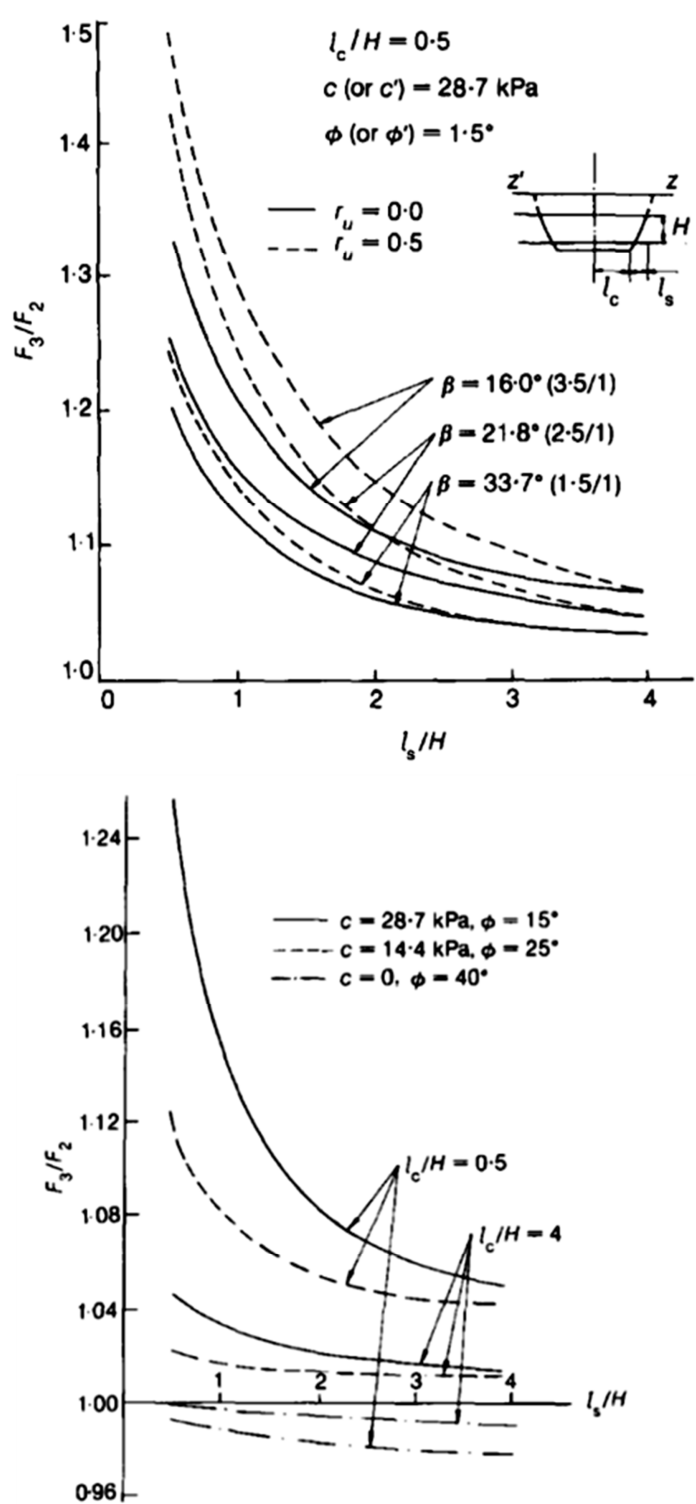

Fig. 5 3D and 2D safety factor stability analysis ration with slope $1 \mathrm{v}: 2.5 \mathrm{~h}$; $\mathrm{ru}=0$ on the left and different slope angles on the right. [7]].

The smallest safety factor, SF, in slope 1: 1.5 conditions and soil parameters $c=0$ and $\phi=40$ was 0.52 while slope stability on other landslide areas with varying depth was also calculated. The results were used to evaluate the reinforcement required using geotextile layers. This study uses geotextile as a reinforcement to resist landslides because it is widely used in the field. Besides, installing geotextile is more comfortable and more economical when compared with other reinforcement. Moreover, requirements for 3-D landslide conditions were compared with those obtained for 2-dimensional analysis. The safety factor ratio for 3-D and 2-D was calculated using the results in Fig. 5 and was found to be 0.98 . This value means the reinforcement needed to withstand landslides with the 2dimensional analysis assumptions applies to 3-dimensional landslides in the field.

The slope stability analysis with soil parameters $\mathrm{c}=7.2$ $\mathrm{kPa}$ and $\phi=30$ and $1: 1.5$ slope also produced a safety factor of less than 1.5. The ratio is more than one. This means the reinforcement needed in the 2-D design is enough and safe against landslides in 3-D and not overestimated in 3-D landslide conditions with a safety factor ratio of 1.05-1.26. Meanwhile, the safety factor was more than 1.5 in other soil parameters, and this indicates the reinforcement is no longer needed.

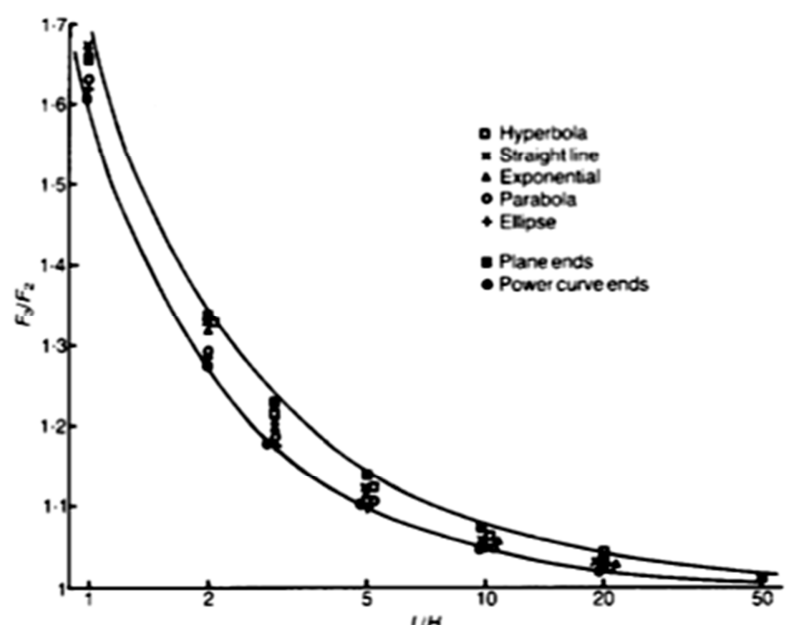

(a)

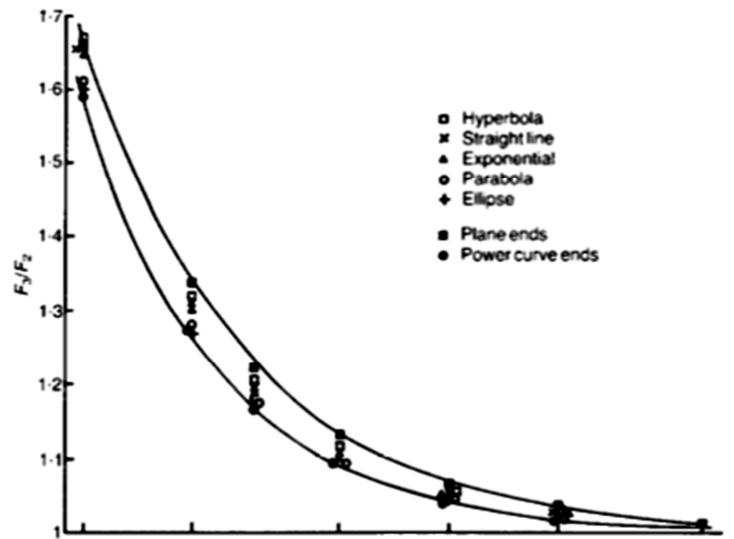

(b)

Fig. 6 The 3-D/2-D safety factor ration for different end shapes with the focus on slope $=30 \mathrm{o}, \mathrm{D}=1$ on the left and slope $=90 \mathrm{o}$ for any value of $\mathrm{D}$ on the right. [13]

The same results were also obtained in slope dimension 1: 2.5 and soil parameters $\mathrm{c}=0 \mathrm{kPa}$ and $\phi=40$ with the lowest safety factor found to be 0.81 in 2-D and 0.79 in 3-D analyses using a ratio of 0.98 . The result is the same as the results obtained at 1:1.5 slope where the reinforcement required to withstand landslides in the 2-dimensional analysis is believed to be applicable in 3-D observed on the field. This finding is generally the same for all other soil parameters. Moreover, slope stability with 1: 3.5 produced a safety factor of more than 1.5 for all parameters, and this means no reinforcement is needed. Table 2 presents a summary of the results.

The results showed the possibility of using the embankment stability analysis from the 2-D method to calculate the reinforcement needed for practical reasons even though the landslide occurring in the field is not plane strain but in three dimensions. The analysis was conducted using homogeneous soil parameters, although the conditions are not homogenous on the field. A slope's stability was also analyzed using $c=0, \phi=40$, and slope $1: 1.5$, which was assumed to stand on a soft clay soil subgrade (Fig. 7b). 
Moreover, the value of the 3-dimensional safety factor obtained from 3-D and 2-D ratio in previous studies on noncohesive soils was recorded to be 0.98 , and this means the reinforcement needed based on 2-D assumption is enough to withstand the real 3-D landslide in the field. No difference was observed in the number of geotextile sheet reinforcement requirements generated from the 2-D landslide analysis compared with the safety factor in the 3-D landslide. However, a variation estimated to be two sheets was recorded with parameters $c=7.2$ and $\phi=30$ due to the subgrade and slope load parameters.

There is a need for further analysis to determine the difference in the amount of reinforcement needed with more soil conditions variations. Some previous studies [30],[31], [32] on the location of critical landslides were observed to have produced the highest reinforcement required with the 2-D landslide assumption used as a comparison. This study, however, found the stability analysis based on 2-D landslide assumption to be strong enough to hold the 3-D landslide as observed from the summary shown in Table 2.

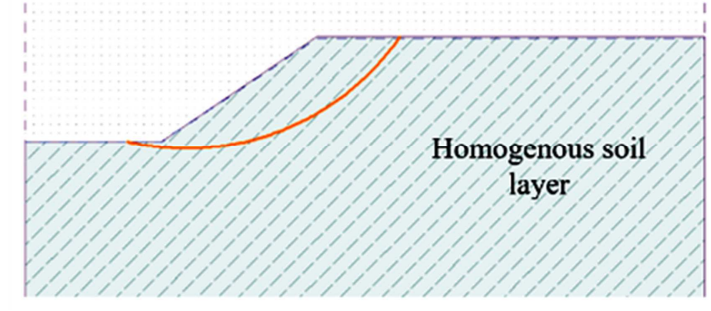

(a)

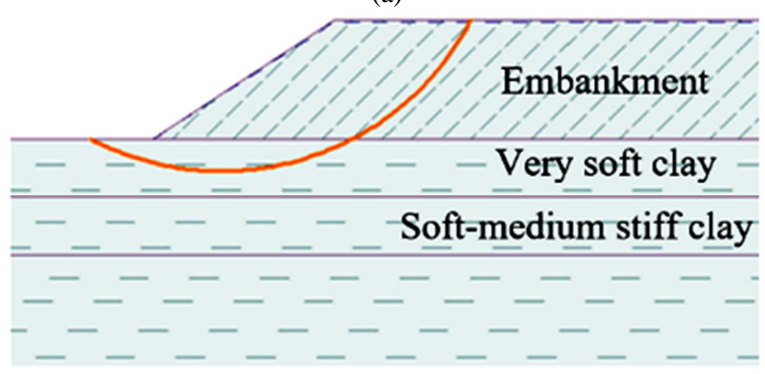

(b)

Fig. 7a (top) The model used for homogenous soil layer; 7b (bottom). The model used for the embankment stands on a soft clay soil subgrade

TABLE II

THe AMount OF GeOteXTILE LAYER WITH Homogenous SoIL SUbGRADE

\begin{tabular}{|c|c|c|c|c|}
\hline Variation & $\begin{array}{c}\text { Safety Factor in 2- } \\
\text { D analysis }\end{array}$ & $\begin{array}{c}\text { Geotextile layer in 2- } \\
\text { D analysis }\end{array}$ & $\begin{array}{l}\text { Safety Factor in } \\
\text { 3-D analysis }\end{array}$ & $\begin{array}{c}\text { Geotextile layer in 3- } \\
\text { D analysis }\end{array}$ \\
\hline \multirow{4}{*}{$\begin{array}{l}\text { Slope } 1: 1.5(\mathrm{c}=0 \text { and } \\
\phi=40)\end{array}$} & 0.52 & 1 & 0.509 & 1 \\
\hline & 0.88 & 3 & 0.86 & 3 \\
\hline & 1.16 & 3 & 1.13 & 3 \\
\hline & 1.03 & 2 & 1.01 & 2 \\
\hline \multirow{4}{*}{$\begin{array}{l}\text { Slope } 1: 1.5(\mathrm{c}=7.2 \\
\mathrm{kPa} \text { and } \phi=30)\end{array}$} & 1.12 & 1 & 1.41 & 1 \\
\hline & 1.33 & 1 & 1.67 & - \\
\hline & 1.31 & 1 & 1.65 & - \\
\hline & 1.46 & 1 & 1.83 & - \\
\hline $\begin{array}{l}\text { Slope } 1: 1,5(c=14 \\
\text { Kpa; } \phi=25)\end{array}$ & 1.54 & - & 1.94 & - \\
\hline $\begin{array}{l}\text { Slope 1:1,5 }(\mathrm{c}=21.6 \\
\mathrm{kpa} ; \phi=20)\end{array}$ & 2.33 & - & 2.93 & - \\
\hline \multirow{5}{*}{$\begin{array}{l}\text { Slope } 1: 2.5(c=0 \text { and } \\
\phi=40)\end{array}$} & 0.93 & 3 & 0.91 & 3 \\
\hline & 1.23 & 2 & 1.20 & 2 \\
\hline & 1.33 & 2 & 1.30 & 2 \\
\hline & 1.35 & 1 & 1.32 & 1 \\
\hline & 0.81 & 1 & 0.79 & 1 \\
\hline $\begin{array}{l}\text { Slope } 1: 2.5(\mathrm{c}=7.2 \\
\text { kpa and } \phi=30)\end{array}$ & 1.37 & 1 & 1.72 & - \\
\hline $\begin{array}{l}\text { Slope 1:2,5 }(c=14 \\
\text { Kpa; } \phi=25)\end{array}$ & 1.81 & - & 2.28 & - \\
\hline
\end{tabular}

TABLE III

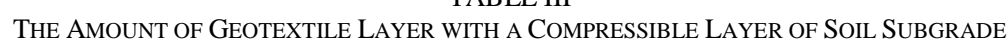

\begin{tabular}{|l|c|c|c|c|}
\hline Variation & $\begin{array}{c}\text { Safety Factor in 2-D } \\
\text { analysis }\end{array}$ & $\begin{array}{c}\text { Geotextile layer in 2-D } \\
\text { analysis }\end{array}$ & $\begin{array}{c}\text { Safety Factor in 3- } \\
\text { D analysis }\end{array}$ & $\begin{array}{c}\text { Geotextile layer in 3-D } \\
\text { analysis }\end{array}$ \\
\hline Slope 1:1.5 $(\mathrm{c}=0$ & 0.87 & 4 & 0.85 & 4 \\
and $\phi=40)$ & 0.85 & 7 & 0.83 & 7 \\
& 0.96 & 7 & 0.94 & 3 \\
\hline Slope $1: 1.5(\mathrm{c}=7.2$ & 1.36 & 3 & 1.33 & 2 \\
kpa and $\phi=30)$ & 0.85 & 4 & 1.07 & \\
\hline
\end{tabular}

Note: the number of geotextiles is assumed with Tultimate $=50 \mathrm{KN} / \mathrm{m}$ ' and the spacing $=0.5$ meter. 
Vestnick [33] proposed establishing the possible connections between 2-D and 3-D models by retrieving the required variables or features from a 2-D model. This involved a certain level of subjectivity concerning the number and size of the variables. Meanwhile, a 3-D model procedure is required to create a 3-D model to retrieve the required variables. This is necessary to estimate the duration as a basis for cost estimation, cost reduction, or TCE (Total Cost Estimation). It is also important to further analyze the creation of regression equations with the index of determination obtained using the most important independent variables in determining the difference between the $2 \mathrm{D}$ and $3 \mathrm{D}$ landslides.

\section{CONCLUSION}

The 3-D approach for slope stability analysis was more compatible with the actual conditions on the field than the 2D approach. Still, designers usually avoid the method because it consumes more time. Previous studies showed that 3-D slope stability analysis produces a safety factor of more than one on cohesive soils and less than 1 (0.97-0.995) on non-cohesive soils. Meanwhile, the safety factor affects the number of reinforcement requirements, and this study showed the value is relatively the same with the use of both $3-\mathrm{D}$ and 2-D analysis. These results were obtained using the safety factor ratio from previous studies conducted with adjusted soil parameters. There is, however, the need for further analysis of other heterogeneous soil parameters to ascertain the generalization of these results.

\section{REFERENCES}

[1] Z. Chen, H. Mi, F. Zhang, and X. Wang, "A simplified method for 3D slope stability analysis," Can. Geot, vol. 683, pp. 675-683, 2003.

[2] M. M. B. Azzouz, By Amr S, "Loaded Areas on Cohesive Slopes," Geotech Eng., vol. 109, no. 5, pp. 724-729, 1983.

[3] O. Hungr, "An extension of Bishop' s simplified method of slope stability analysis to three dimensions," Geotechnique, vol. 37, no. 1, pp. 113-117, 1987.

[4] Y. J. Chen,.Y., Yin, J.H., Wang, "The Three-Dimensional Slope Stability Analysis: Recent Advances and a Forward Look," Adv. Earth Struct., no. Gsp 151, pp. 1-42, 2006.

[5] C. Huang, C. Tsai, and Y. Chen, "Generalized Method for ThreeDimensional Slope Stability Analysis," J. Geotech. Geoenvironmental Eng. Am. Soc. Civ. Eng., no. October, pp. 836848, 2002.

[6] C. Y.M., "Three-dimensional asymmetrical slope stability analysisExtension of Bishops, Janbus, and Morgenstern Prices techniques," J. Geotech. Geoenvironmental Eng., vol. 12, no. 133, pp. 1544-1555, 2007.

[7] R. H. Chen and J. Chameaut, "Three-dimensional limit equilibrium analysis of slopes," Geotechnique, vol. 32, no. 1, pp. 31-40, 1982.

[8] E. Bahsan and R. Fakhriyyanti, "Comparison of 2D and 3D Stability Analyses for Natural Slope," Int. J. Eng. Technol., vol. 7, no. July 2016, pp. 662-667, 2018.

[9] A. Li, Two- and Three-Dimensional Stability Analyses for Soil and Rock Slopes, no. August. 2009.

[10] H. Z. Dana, R. K. Kakaie, R. Rafiee, and A. R. Y. Bafghi, "Effects of geometrical and geomechanical properties on slope stability of open- pit mines using 2D and 3D finite difference methods," J. Min Environ., vol. 9, no. 4, pp. 941-957, 2018.

[11] M. D. Fredlund, D. Ph, D. G. Fredlund, D. Ph, L. Zhang, and D. Ph, "Moving from 2D to a 3D Unsaturated Slope Stability Analysis," 2015, pp. 1-10.

[12] A. K. Kondalamahanthy, 2D and 3D Back Analysis of the Forest City Landslide (South Dakota). 2013.

[13] W. Peng, J. Mo, and Y. Xie, "Comparison for the results from 2D and 3D analysis for slope stability," Appl. Mech. Mater., vol. 93, pp. 255-259, 2011.

[14] M. S. Saeed, P. Maarefvand, and E. Yaaghubi, "Two and threedimensional slope stability analyses of final wall for Miduk mine," Int. J. Geo-Engineering, 2015.

[15] L. Z. Murray D. Fredlund ,Delwyn G. Fredlund, "Moving from 2D to a 3D Unsaturated Slope Stability Analysis," in PanAm Unsaturated Soils, 2017

[16] D. Wines, "A comparison of slope stability analyses in two and three dimensions," vol. 116, no. October 2015, pp. 12-14, 2016.

[17] H. Ersoy, "2D and 3D numerical simulations of a reinforced landslide: A case study in NE Turkey," J.Earth Syst. Sci, vol. 129, no. April, 2020.

[18] H. J. Hovland, "Three-dimensional slope stability analysis method," ASCE, vol. 103, no. GT 9, pp. 971-986, 1977.

[19] D. J.M., Soil strength and slope stability. Hoboken,NJ: John Wiley, 2005.

[20] G. J.L., Sherard; R.J.,Woodward; S.F., Earth rock dams: Engineering problems of design and construction. New york: John Wiley and Sons, 1963.

[21] R. H. Chen and J. N. Hutchinson, "limit equilibrium analysis of slopes," Geotechnique, vol. 33, no. 1, pp. 31-40, 1983.

[22] K. Akhtar, Three-Dimensional Slope Stability Analyses for Natural and Manmade Slopes. 2011.

[23] M. Dong, H. Hu, and J. Song, "Combined methodology for three dimensional slope stability analysis coupled with time effect: a case study in Germany," Environ. Earth Sci., vol. 77, no. 8, pp. 1-15, 2018.

[24] T. D. Stark, "Selecting Minimum Factors of Safety for 3D Slope Stability Analyses," in Geo-Risk 2017, no. 1998, 2017, pp. 259-266.

[25] N. Analysis, "water Topographic E ff ects on Three-Dimensional Slope," pp. 1-24, 2020.

[26] A. Chakraborty and D. Goswami, "State of the art: ThreeDimensional (3D) Slope-Stability Analysis," Int. J. Geotech. Eng., vol. 6362, no. November, pp. 1-6, 2016

[27] H. E. M. C. F. Azevedo, N.M. Souza, M.T.M.G. Silva, "Use of threedimensional slope stability model and probabilistic method for landslides hazard analysis triggered by rainfall," in Landslides and Engineered Slopes. Experience, Theory and Practice, 2016.

[28] A. Chakraborty and D. Goswami, "Three-dimensional (3D) slope stability analysis using stability charts," Int. J. Geotech. Eng., vol. 6362, no. May, pp. 1-8, 2018.

[29] C. Gens, A. Hutchinson, J.N., "Three-dimensional analysis of slides in cohesive soils," Geotechnique, vol. 38, no. 1, pp. 1-23, 1988.

[30] P. T. K. Sari and Y. Lastiasih, "A General Formulation to Describe the Empirical Prediction of The Critical Area of A Landslide," JESTEC, vol. 13, no. 8, pp. 2379-2394, 2018.

[31] P. T. K. Sari and Y. Lastiasih, "Proposed Design Graphs of Geotextile Reinforcement on Soft Clay under Various Field Conditions," Civ. Eng. Dimens., vol. 18, no. 2, pp. 109-116, 2017.

[32] P T K Sari and Y Lastiasih, "The Empirical Prediction of The Critical Area of Road Embankment Landslide Using Limit Equilibrium Method the Empirical Prediction of The Critical Area of Road Embankment Landslide Using Limit Equilibrium Method," in JIC-CEGE 2019 IOP Conf. Series: Earth and Environmental Science, 2020, pp. 1-8.

[33] Vestnik S, "Retrieved Features of $2 \mathrm{~F}$ and 3D Models from CAD as decision support for production Time/cost estimation," 2011. 